\title{
Kurumlar, Cinsiyet ve Yolsuzluk İliş̧kisi: Merkezi ve Doğu Avrupa Ülkeleri Üzerine Panel VAR Analizi
}

\author{
Pınar ÇUHADAR*
}

\begin{abstract}
Öz
Yolsuzluk, özel çıkarlar elde etmek için kamu makamlarının bir birey veya grup tarafından suiistimal edilmesidir. Literatürde kadın ve erkeklerin cinsiyetlerine özgü davranış kalıplarına sahip olduğu ve bu davranıs kalıplarının yolsuzluk yapmaya eğilimi etkilediği tartıșılmaktadır. Bu çalıșmanın amacı sosyalist yönetim döneminde yolsuzluğun yüksek düzeylere eriștiği ve rejim değișimi sonrası geçmiș kurumların etkisinin sürdüğü Merkezi ve Doğu Avrupa ülkelerinde liberal demokratik kurumlar, cinsiyet ve yolsuzluk arasındaki ilişkiyi incelemektedir. Çalışmada kadınların güçlendirilmesi, parlamentodaki kadınların temsil oranı ve liberal demokratik kurumların kamudaki yolsuzlukla ilișkisi panel VAR analizi araștırılmıștır. Analiz neticesinde Merkezi ve Doğu Avrupa ülkelerinde cinsiyet ve yolsuzluk arasında Granger nedensellik bulunamazken, bulgular liberal demokratik kurumlarla yolsuzluklar arasında ilişki olduğunu desteklemektedir.
\end{abstract}

Anahtar kelimeler: Yolsuzluk, cinsiyet, kurumlar, panel veri, VAR modeli

Jel Kodu: C23, J16, 057, P37

\section{Institutions, Gender and Corruption Relations: Panel VAR Analysis on Central and Eastern Europe Countries}

\begin{abstract}
Corruption is the abuse of public office for private gains by indivudials or groups. It is discussed in the current literature that women and men have behavioural patterns related to their gender and these patterns' can affect their tendency towards corruption. The aim of this study is to seek a gender-and corruption relation in Central and Eastern European Countries where there was a high level of corruption during socialist regimes accompanied with the sustaining imression of past institutions. The study applied panel VAR (vector autoregressive) analysis to examine women's empowerment and the representation of women in parliament and liberal democratic institutions, and their linkages with corruption. As a result of the analysis, even if Granger causality is not found between gender and corruption in Central and Eastern European countries, findings support relations between liberal democratic institutions and corruption.
\end{abstract}

Keywords: Corruption, gender, institutions, panel data, VAR models

Jel Code: C23, J16, 057, P37

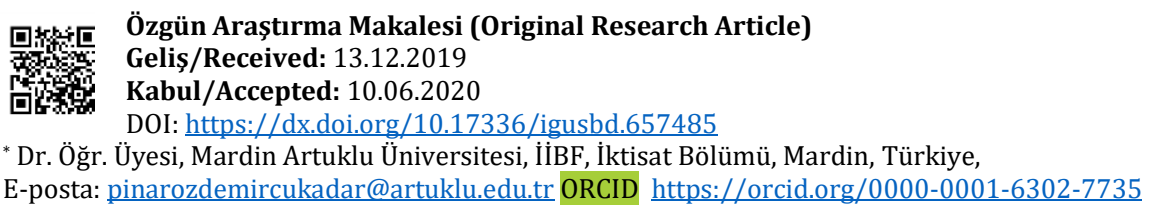




\section{Giriş}

Yolsuzluk, kamu makamlarının zimmete geçirme, nepotizm, rüşvet, irtikap, nüfuz ticareti, dolandırıcılık vb. yollarla bir birey veya grup tarafından özel çıkarlar için kullanılmasıdır (Dininio, Kpundeb \& Leiken, 1999, s. 4). Kamu kaynaklarının özel çıarlar için kullanılması yalnız ekonomik değil, sosyal ve siyasal sonuçları da beraberinde getirmektedir. Yapılan araştırmalar, bir ülkenin ekonomik gelişmişlik düzeyi yükseldikçe, gelir dağılımı adaleti sağlandıkça, uluslararası ticarette ağırlığı arttıkça ve eğitim seviyesi ilerledikçe yolsuzlukların azaldığını ortaya koymaktadır. Bu değişkenlerin yanı sıra yolsuzluk, doğal kaynaklarca zengin, sömürge geçmişi bulunan veya etnik ve dinsel çatışmaların bulunduğu ülkelerde önemli bir sorun haline gelmektedir (Sung You \& Khagram, 2004, s. 6-7). Bu ülkeler çoğunlukla demokratik yönetimlerin temel koşulu olan hukuk güvenliği ve denge denetim mekanizmalarının bulunmadığı ülkelerdir.

Stensöta, Wängnerud ve Svensson (2015)'e göre yolsuzluk ve cinsiyet arasındaki ilişki kurumsal boyutludur ve toplumsal cinsiyet ile grup davranışları arasındaki ilişkiden kaynaklanmaktadır. Seleim ve Bontis (2009)'e göre kültürel olarak belirsizlikten kaçınma, gelecek odaklı olma, kurumsal kolektivizm, insan odaklı olmak, performans odaklı olmak gibi davranıș kalıpları yolsuzluk ile korelasyon içindedir. Branisa, Klasen ve Ziegler (2010)'de kurumların gelişmenin, sosyal kurumlar ise cinsiyet eşitsizliğinin belirleyicisi olduğunu vurgulamaktadır. Martin(2004)'e göre, konu bu açıdan değerlendirildiğinde toplumsal cinsiyet algısı bir "sosyal kurumdur" ve biyolojik özelliklerin ötesinde bir değerlendirmeyi gerektirmektedir. Toplumsal cinsiyet bir kurum olarak tanımlandığında olgu ve olaylarla ilişkisi değerlendirilirken konunun ideolojik nitelik kazandığı, toplumsal uygulamalar, kısıtlar, çatışmalar, siyasal ve ekonomik gücün dağılımı üzerinde etki yarattığı da dikkate alınmalıdır. Yolsuzluğun ekonomik ve siyasal boyutu birçok araştırmaya konu olmakla birlikte toplumsal cinsiyet ve kadınlar üzerine yapılan araştırmalar göreceli olarak daha sınırlı kalmakta ve sonuçları üzerinde de uzlașılamamaktadır.

Sung (2012), kadınların tarihsel, dinsel ve kültürel olarak kamusal alanda eksik temsil edilen cinsiyet olmalarından dolayı daha çok ayrımcılığa ve sosyal dışlanmaya uğrayan grup olduğunun altını çizmektedir. Günümüzde kadınların nüfusa oranları dikkate alındığında hane içi ve ulusal siyasete ait karar alma mekanizmalarında temsilleri yetersiz görülmektedir. Bu durum kadınların yapabilirliğini ekonomik, siyasal ve sosyal alanlarda sınırlamaktadır. Sung (2012)'ye göre tüm bu eşitsizlikler yolsuzluğu da beslemektedir. Bu bakımdan Akhmetova (2014)'e göre yolsuzluk karşıtı çalışmalar aynı zamanda kadınların güçlendirilmesini ve cinsiyet eșitliğini de kapsamalıdır. Kadınların karar alma mekanizmalarında rol alması yolsuzlukla mücadele içinde önemli bir adım olarak görülmektedir.

Çalıșmaya konu olan Merkezi ve Doğu Avrupa (MDA) ülkeleri, 1990'lı yılların başında sosyalizmden piyasa ekonomisine geçmiş, bir dizi ekonomik, siyasal ve sosyal şoka maruz kalmıș ülkelerdir. MDA ülkelerinin sosyalist dönemde temel problemleri, bürokrasinin kamu hizmetlerinin sunumundaki katı uygulamaları, kamu sektörü tarafından sunulan hizmetlerin kaliteli olmaması, merkezi yönetimin yerelin ihtiyaçlarını dikkate almaması, yolsuzluk ve rüşvet ilişkilerinin devlet içinde olağanlaşması olarak sıralanmaktadır. Bu ülkeler günümüzde liberal ekonomik ve siyasal sistemi benimsemiş olmakla birlikte kamu sektörünün işleyişi halen geçmiş kurumların etkisi altında görünmektedir (Bulğurcu \& Özdemir, 2015, s.523-525; Özdemir Çukadar, 2017, s.245251). Batory (2012)'e göre, MDA ülkelerinde yolsuzluk karşıtı önlemlerin başarısız olmasının başlıca nedenleri; yasal düzenlemelerin güvenilir olmaması, cezaların caydırıcı 
olmaması, yolsuzlukla mücadele yasaları hazırlanırken sosyal normların dikkate alınması dolayısı ile vatandaşların yasalara uyumunun sağlanamamasıdır.

$\mathrm{Bu}$ çalışmanın amacı sosyalist yönetim döneminde yolsuzluğun yüksek düzeylere eriștiği ve rejim değişimi sonrası geçmiş kurumların etkisini sürdürdüğü görülen Merkezi ve Doğu Avrupa ülkelerinde liberal siyasal kurumlar, cinsiyet ve yolsuzluk arasındaki ilişskiyi incelemektedir. Çalışmada kadınların güçlendirilmesi, parlamentodaki kadınların temsil oranı ve liberal demokratik kurumların kamudaki yolsuzlukla ilişkisi panel VAR analizi ile araştırılmıştır. Çalışmanın temel kısıtı demokrasi, yolsuzluk vb. konularda oluşturulan veri setlerinin güvenilirliğinin sorgulanmasının yanı sıra veri setlerindeki eksiklikler nedeni ile rejim değişimi geçiren ülkelerden yalnız dokuz tanesinin (Çek Cumhuriyeti, Estonya, Macaristan, Litvanya, Letonya, Polonya, Romanya, Slovakya, Slovenya) analize dâhil edilebilmesidir. Çalıșmanın temel katkısı ise yolsuzluğun önemli bir kurumsal problem haline geldiği MDA ülkelerinde liberal demokratik kurumlar ve cinsiyetin etkisinin ortaya konmasıdır.

Çalışmanın birinci bölümünde ele alınan MDA ülkelerinde cinsiyet eşitsizliğinin genel durumu kısaca özetlenecektir. Çalışmanın ikinci bölümünde konu ile ilgili yapılmış geçmiş çalışmaların bulgularının ortaya konduğu literatür taraması yer almaktadır. Üçüncü bölümde veri seti ve dördüncü bölümde yöntem tanıtılmakta, beșinci bölümde bulgular ve tartışma ortaya konmaktadır. Sonuç bölümünde genel bir değerlendirme yapılmaktadır.

\section{Merkezi ve Doğu Avrupa'da Cinsiyet Eşitsizliğinin Genel Görünümü}

MDA ülkeleri cinsiyet eşitliği konusunda birbirinden ayrı niteliklere sahiptir. Cinsiyet eşitsizliğini ekonomiye katılım ve fırsatlar, eğitime katılım, sağlık ve yaşam ve siyasi güçlendirme başlıkları altında inceleyen Küresel Cinsiyet Açığı Raporu (2018) sonuçları da bu ayrışmayı destekler niteliktedir. Tablo 1, seçili MDA ülkelerinde cinsiyet açığı endeksinden elde edilen sonuçları göstermektedir:

\begin{tabular}{|l|l|l|l|l|l|}
\hline Ülke & $\begin{array}{l}\text { Küresel } \\
\text { Endeks } \\
\text { Sırası }\end{array}$ & $\begin{array}{l}\text { Ekonomik Katılım ve } \\
\text { Fırsatlar Sırası }\end{array}$ & $\begin{array}{l}\text { Eğitime } \\
\text { Katılım } \\
\text { Sırası }\end{array}$ & $\begin{array}{l}\text { Sağlık ve } \\
\text { Yaşam Sırası }\end{array}$ & $\begin{array}{l}\text { Siyasi } \\
\text { Güçlendirme } \\
\text { Sırası }\end{array}$ \\
\hline Slovenya & 11 & 15 & 29 & 1 & 22 \\
\hline Letonya & 17 & 10 & 1 & 1 & 42 \\
\hline Litvanya & 24 & 21 & 53 & 1 & 41 \\
\hline Estonya & 33 & 42 & 1 & 42 & 51 \\
\hline Polonya & 42 & 50 & 51 & 1 & 50 \\
\hline Romanya & 63 & 53 & 56 & 1 & 89 \\
\hline $\begin{array}{l}\text { Çek } \\
\text { Cumhuriyeti }\end{array}$ & 82 & 87 & 1 & 1 & 91 \\
\hline Slovakya & 83 & 83 & 66 & 42 & 142 \\
\hline Macaristan & 102 & 68 & 1 & 1 & 79 \\
\hline
\end{tabular}

Tablo1: Seçili MDA Ülkelerinin Cinsiyet Açı̆̆ı Sıralamaları

Kaynak: Dünya Ekonomik Forumu, Küresel Cinsiyet Açı̆̆ı Raporu¹, 2018.

\footnotetext{
${ }^{1}$ World Economic Forum, The Global Gender Gap Report
} 
Tablo 1 incelendiğinde MDA ülkelerinin ekonomik katılım ve fırsatlar, eğitime katılım, sağlık ve yaşam, siyasal güçlendirme alt endekslerinde elde ettikleri sıralamalar görülmektedir. Slovenya kriterlerin tamamında en başarılı MDA ülkesi olarak ön plana çıkarken, Macaristan sıralamalarda oldukça geride kalmaktadır. Tabloda dikkat çeken bir diğer unsur cinsiyet eșitsizliği konusunda ülkelerin birbirlerinde farklı nitelik göstermesidir. MDA ülkeleri eğitim ve sağlık konusundaki cinsiyet açığını kapatmada kısmen daha başarılı olurken ekonomik katılım ve siyasi güçlendirme konusunda açık yüksek görünmektedir.

\section{Literatür Taraması}

Kadınların toplumsal cinsiyet rolleri, kurumlar ve yolsuzluk arasındaki ilişkileri araştırmak için ekonometrik ve deneysel yöntemler kullanılarak birçok çalışma yapılmıştır. Bu çalışmaların toplumsal cinsiyet, kurumlar ve yolsuzluk konusunda birbiri ile tutarlı olmayan farklı sonuçlara ulaştığı görülmektedir. Cinsiyet ve yolsuzluk araştırmalarını;

- Kadınların etik değerlere daha bağlı olduğunu savunan yaklaşımlar

- Kadınların riske karşıt olduğunu ve güç ilişkilerinden dışlandıkları için yolsuzluk yapmadıklarını savunan yaklaşımlar

- Toplumsal cinsiyet ve yolsuzluk arasında herhangi bir ilişki olmadığını, yolsuzluğun kurumlarla iliş̧ili olarak açıklanabileceğini savunan yaklaşımlar olmak üzere üç grupta ele almak mümkün görünmektedir.

Dollar, Fisman ve Gatti (1999), öncü çalışmalarında 1985-1995 yılları için 100'den fazla ülke üzerine panel veri analizi yapmış; (yolsuzlukların azaltılması için kadınların karar alma mekanizmalarında yer alması gerektiğini savunan Dünya Bankası'nın görüşleri ile tutarlı olarak) kadınların yönetimlerde söz sahibi olmasının yolsuzlukları azaltarak yönetimlerin daha dürüst olmasını sağlayacağı sonucuna ulaşmışlardır. $\mathrm{Bu}$ araștırmanın temelinde yatan düşünce kadınların toplumsal ve ekonomik olaylara daha duyarlı, daha yardımsever ve etik değerlere daha bağlı olduğu, kadınların kamusal ortak malları kişisel kazançları için daha az feda edeceği görüşüdür. Rivas (2008) yaptığı deneysel araştırmada emek piyasası ve siyasette kadın varlığının daha az yolsuzluğa neden olduğu, yöneticileri erkek olan firmaların rüşvet teklif etme eğiliminin \%80 iken kadınlarınkinin \%65 değerine ulaştığı sonucuna varmıştır. Torgler ve Valev (2010), 1981-1999 dönemi için Batı Avrupa ülkelerinde cinsiyetin davranış kalıpları üzerindeki etkisini araştırdıkları çalışmalarında Dünya ve Avrupa Değerler anketinden yararlanarak probit model kurmuşlar; kadınların yolsuzluklara taraftar olmamakla birlikte vergiden kaçınma davranışına eğilimli olduklarını saptamışlardır. Çalışma bulguları, kadınların yönetimde ya da kamuda görev almasının yolsuzlukları azaltacağını desteklemektedir. Jha ve Sarangi (2018), 17 Avrupa ülkesi üzerine araç değişken kullanarak yaptıkları panel veri analizinde şartlı olabilirlik oranı yaklaşımını kullanmışlardır. Çalışmadan elde edilen bulgular, kadınların parlamentoda yer almalarının yolsuzlukla negatif ve anlamlı olarak ilişki içinde olduğunu diğer ekonomik aktivitelerle yer almalarının yolsuzluk üzerinde herhangi bir etkisi olmadığı sonucunu desteklemektedir. Esarey ve Schwindt-Bayer (2017), hesap verilebilirliğin olduğu ülkelerde kadınların mecliste temsili ve yolsuzluk arasında güçlü negatif ilişki olduğunu bulmuştur. Bu noktada çalışmada seçim güvenliği ve kadınların yolsuzlukla ilişkisi arasında ilişki kurulmuştur.

Goetz (2007), Frank, Lambsdorff ve Boehm (2011), Sung (2012) ise konu ile ilgili ampirik çalıșma yapmanın zorluklarını vurgulamış; geçmiş çalışmaların eksikliklerini ortaya koymuş ve yaptıkları ampirik araştırmalarda Dollar, Fisman ve Gatti(1999)'nin 
bulgularında farklı sonuçlara ulaşmışlardır. Goetz (2007), feminist yazının da yolsuzluk ve kadınlar arasındaki ilişkiyi ele almaktan sakınmasını da konunun zorluğuna bağlamış; ampirik çalışmalarda yolsuzluğun ölçülmesinin zorluklarına dikkat çekmiştir Bununla birlikte. Goetz (2007), kadınların erkeklerin hakim olduğu ulusal ve uluslararası sistemin güç iliş̧ilerinden dışlandı̆̆ı için daha az yolsuzluk yaptığını çalışmada vurgulamaktadır. Alatas, Cameron, Chaudhuri, Erkal ve Gangadharan (2008), kadın ve erkeklerin toplumsal rollerinin ayrışması yolsuzluk karşısındaki davranış şekillerini etkileyeceği görüşünden hareketle Avusturalya, Hindistan, Singapur, Endonezya'da yaptıkları araștırmada kadınların davranış kalıplarının kültürle yakından ilişkili olduğu ve genelleyemeyeceği sonucuna ulaşmışlardır. Buna göre, ülkeler arasında kıyaslama yapıldığında erkeklerin davranışları arasındaki değişkenliğin kadınlara nazaran daha az olduğu görülmüștür. Frank, Lambsdorff ve Boehm (2011), konu ile ilgili çalışmaların en önemli kısıtının ters nedensellik ve ihmal edilen değişkenler olduğunu savunmaktadır. Frank vd. (2011), oyun teorisine dayalı olarak yaptıkları deneysel çalışmada cinsiyetler arasında rüşvet alma ve verme konusunda anlamlı bir farklılık olmadığı sonucuna varmışlardır. Sung (2012), toplumsal cinsiyet ve yolsuzluk arasındaki ilişkileri araştırmak üzere yapılan çalışmaları adil cinsiyet (Dollar vd.1999) ve liberal demokratik ekonomik ve sosyal yapıyı dikkate alan adil sistem yaklaşımı olarak ayrıştırmakta; ampirik olarak yapılan çalışmaların eksik veya hatalı noktalarını ortaya koymaktadır. Sung (2012), 204 ülke üzerine 1998-2004 yıllarını kapsayan panel veri analizi yapmış; ne kadın yöneticinin ne de kadınların yönetimde temsilinin artması ile yolsuzluk arasında herhangi bir ilişki saptayamamıștır Sung (2012)'ye göre yolsuzluk cinsiyetten ziyade liberal demokratik kurumların işlerliği ile alakalı görünmektedir. Barnes ve Beaulieu (2014)'de kadınların lider olmalarının olağanlaştığı durumlarda kadın yöneticilerin yolsuzluğu azaltıcı etkisinin sınırlı olduğu bulgusuna ulaşmıșlardır.

\section{Veri}

Kurumlar, cinsiyet ve yolsuzluk ilişkisinin araştırıldığı çalışmada analize dâhil olan MDA ülkeleri Çek Cumhuriyeti, Estonya, Macaristan, Litvanya, Letonya, Polonya, Romanya, Slovakya, Slovenya'dır. Ülke sayısının dokuz ile sınırlı kalmasının temel nedeni diğer MDA ülkelerine ait veri setlerinde yeterli verinin olmamasıdır. Çalışmada analiz edilen dönem 1998-2017 dönemidir. Kullanılan veriler Yönetim Kalitesi Enstitüsü ${ }^{2}$ web sayfasından alınmıștır. İlgili enstitü sosyoekonomik ve politik veri setlerinin tamamına ulaşılabilirliği sağlayan bir çalışma yürütmektedir. Çalışmada kullanılan verilerin amaçları ve tanısal istatistikleri Tablo 2'de özetlenmektedir.

\footnotetext{
${ }^{2}$ Quality of Government Institute
} 


\begin{tabular}{|c|c|c|c|c|c|c|c|}
\hline Veri & Kisaltma & Kaynak & Amaç & Ortalama & \begin{tabular}{|l|} 
Standart \\
Hata \\
\end{tabular} & Min. & Maks \\
\hline $\begin{array}{l}\text { kamudaki } \\
\text { yolsuzluklar }\end{array}$ & kamuylsz & $\begin{array}{l}\text { Varieties of } \\
\text { Democracy } \\
\text { Project }\end{array}$ & $\begin{array}{l}\text { Kamu sektöründeki } \\
\text { rüşvet ve zimmete } \\
\text { geçirme gibi yasa dışı } \\
\text { faaliyetleri } \\
\text { göstermektedir. }\end{array}$ & 2.6 & 0.52 & 0.65 & 3.31 \\
\hline $\begin{array}{l}\text { kadının } \\
\text { güçlendirilmesi }\end{array}$ & kgüçl & $\begin{array}{l}\text { Varieties of } \\
\text { Democracy } \\
\text { Project }\end{array}$ & $\begin{array}{l}\text { Kadınların } \\
\text { kapasitelerini artırarak } \\
\text { tercihlerini daha iyi } \\
\text { ortaya koymaları ve } \\
\text { toplumsal karar alma } \\
\text { süreçlerine daha etkin } \\
\text { katılmalarını } \\
\text { sağlayacak sivil } \\
\text { özgürlükler, sivil } \\
\text { toplum ve siyasi katılım } \\
\text { faaliyetlerini } \\
\text { içermektedir. }\end{array}$ & 0.92 & 0.029 & 0.84 & 0.97 \\
\hline $\begin{array}{l}\text { liberal } \\
\text { demokrasi }\end{array}$ & libdem & $\begin{array}{l}\text { Varieties of } \\
\text { Democracy } \\
\text { Project }\end{array}$ & $\begin{array}{l}\text { Hukukun üstünlüğü, } \\
\text { bağımsız yargı, denge } \\
\text { ve denetim } \\
\text { mekanizmalarının } \\
\text { işlerliği gibi liberal } \\
\text { demokratik unsurları } \\
\text { içermektedir. }\end{array}$ & 0.74 & 0.10 & 0.45 & 0.86 \\
\hline $\begin{array}{l}\text { meclisteki kadın } \\
\text { sayısı }\end{array}$ & meclisks & $\begin{array}{l}\text { World } \\
\text { Develop- } \\
\text { ment } \\
\text { Indicators }\end{array}$ & $\begin{array}{l}\text { Kadın parlamenter } \\
\text { sayısının toplam } \\
\text { parlamenter sayısına } \\
\text { oranın göstermektedir. }\end{array}$ & 17.33 & 6.1 & 7.3 & 36.7 \\
\hline
\end{tabular}

Tablo2.Veri Setinin Genel Özellikleri

Tablo 2'de tanısal istatistikler incelendiğinde standart hatanın en düşük olduğu değişkenin kadının güçlendirilmesi, en yüksek olduğu değişkenin ise meclisteki kadın sayısı olduğu görülmektedir. Buna göre ülkeler arasında kadınların siyaset katılım ve karar alma mekanizmalarındaki rolü daha yüksek oranda farklılaşmaktadır. Bu farklılaşmanın cinsiyet eșitsizliğinin temelini oluşturduğu düşünülmektedir.

\section{Yöntem}

Panel veri analizinde ilk adım serilerde yatay kesit bağımlılığı ve heterojenliğin incelenmesidir. Çalışmada zaman boyutunun, paneldeki birim sayısından daha fazla olması, analiz edilen MDA ülkelerinin ekonomik, siyasal ve sosyal etkileşimlerinin bulunması serilerde yatay kesit bağımlılı̆̆ının ve heterojenliğin dikkate alınmasını zorunlu kılmaktadır. Ayrıca analiz için uygun birim kök testinin tespit edebilmek ve panel VAR modeline dayalı olarak yapılacak nedensellik analizinin sapmalı sonuçlar vermesini engellemek içinde yatay kesit bağımlılığı ve heterojenlik test edilmelidir.

Yatay kesit bağımlılı̆̆ını saptamak için birçok test geliştirilmiştir. Küçük birim sayısı (N) ve göreli olarak geniş zaman (T) boyutu için Breusch ve Pagan (1980) tarafından geliştirilen LM $^{3}$ (Langrange Çarpanı) testine başvurulabilmektedir. LM testi istatistiği denklem 1'de gösterilmiştir. $\hat{p}_{i j}$ modelin en küçük kareler yöntemi ile tahmin edilmesi sonucu elde edilen kalıntıların ikili gruplar halinde korelasyon tahminidir.

$$
\mathrm{LM}=T \sum_{i-1}^{N-1} \sum_{j=i+1}^{N} \hat{p}_{i j}^{2}
$$

\footnotetext{
${ }^{3}$ Langrange Multiplier
} 
Panel veride parametrelerin homojenliğinin sınanmasında ise diğer testlere kıyasla daha etkin sonuçlar verdiği kabul edilen Swamy S ve Pesaran ve Yamagata (2008) $\Delta$ testleri kullanılacaktır. Bu testlerde sınanacak hipotez $\mathrm{H}_{0}: \beta_{1}=\beta$ olup parametrelerin homojen olduğunu ifade etmektedir (Yerdelen Tatoğlu, 2020, s. 97).

Panel veride yatay kesitin tespit edilmesi halinde ikinci nesil birim kök testleri kullanılmaktadır. $\quad \mathrm{T}>\mathrm{N}$ olması durumunda Görünürde İlişkisiz Regresyon (SUR) ${ }^{4}$ mantığına dayalı ve $\beta^{\prime}$ ların panel boyunca değişimine dolayısıyla heterojenliğe izin veren (Narayan ve Narayan, 2007, s.239) birim kök testlerinden biri MADF5 (Çok Değişkenli Genişletilmiş Dickey Fuller) testidir. Test tek denklemli ADF testinin panelin her bir birine ayrı ayrı uygulanmasını gerektirmektedir. Testin boş hipotezi denklem 2'de gösterilmektedir. Buna göre;

$$
\mathrm{H}_{0}: \sum_{j=1}^{k} \hat{p}_{i j}-1=0 \quad \forall \mathrm{i}=1, \ldots, \mathrm{N}
$$

Sıfır hipotezi altında, tüm serilerin durağan olmadığı varsayılmaktadır.

$\operatorname{VAR}^{6}$ (Vektör Otoregresif) zaman serilerinde tüm değişkenleri içsel olarak kabul eden, çok değişkenli eş anlı denklem sistemlerine alternatif olarak Sims (1980) tarafından geliştirilen bir modeldir (Abrigo \&Love, 2015, s.1). Panel VAR modellerinin üç temel özelliği mevcuttur. Birinci özellik i birimi için kurgulanan modele bütün birimlerin içsel değişkenlerinin dâhil edilmesidir. İkinci temel özellik uit 'lerin tüm birimleri boyunca aralarında korelasyon bulunmasıdır. Üçüncü özellik ise sabit terim, eğim ve uit'lerin şoklarının varyanslarının birime özgü olması yani yatay kesitsel heterojenliğin olmasıdır. $\mathrm{Bu}$ özellik makroekonomide kullanılan panel VAR modellerini mikroekonomide kullanılan ve homojen grupları ele alan sektörel modellerden ayırmaktadır. Makroekonomik çalışmalarda yatay kesitsel heterojenliğe sahip örneklemleri ele alan araștırmalar, bu özelliği göz ardı edip homojenlik varsayımı yaparak analizlerine devam etmektedir (Canova \& Ciccarelli, 2013, s.8).

$$
\begin{aligned}
& Y_{i t}=Y_{i t-1} A_{1}+Y_{i t-2 A 2}+\ldots . . .+Y_{i t-p+1} A_{p-1}+Y_{i t-p} A_{p}+X_{i t} B+u_{i t}+e_{i t} \\
& i \in\{1,2,---N\}, t \in\{1,2 \ldots T\}
\end{aligned}
$$

$Y_{\text {it }}(1 \mathrm{xk})$ bağımlı değișken vektörü, $X_{\text {it }}(1 \mathrm{x} 1)$, dıșsal ortak değişken, $u_{i}$ ve $e_{i t}(1 x k)$ bağımlı değişken spesifik sabit ekiler ve idiyosinkratik hatadır. (kxk) $A_{1}, A_{2}, A_{p-1}, A_{p}$ ve (1xk) B tahmin edilen parametredir. Tahminlerde etkinliği arttırmak için daha uzun döneme ait gecikmeler araç değişken olarak kullanılmaktadır. Bu durumun yanlı tahminlere yol açmaması için $\mathrm{GMM}^{7}$ (Genelleştirilmiş Momentler Yöntemi) tahmincisine başvurulmaktadır. Modellerde uygun gecikme uzunluğunun bulunması ise maksimum olabilirlik yaklaşımına dayalı Akaike bilgi kriteri ${ }^{8}$ (AIC), Bayesyan bilgi kriteri ${ }^{9}$ (BIC) ve Hannan Quinn bilgi kriterine ${ }^{10}$ başvurulmaktadır Abrigo ve Love (2015), Andrews ve Lu (2001), Hansen (1982)'nin aşırı tanımlayıcı kısıtlarının istatistiklerini kullanarak GMM için tutarlı moment ve model seçim kriteri geliştirdiğini ortaya koymaktadır.

\footnotetext{
${ }^{4}$ Seemingly Unrelated Regression

${ }^{5}$ Multivariate Augmented Dickey Fuller

${ }^{6}$ Vektor Autoregression

${ }^{7}$ Generalized Method of Moments

${ }^{8}$ Akaike Information Criteria

${ }^{9}$ Bayesian Information Criteria

${ }^{10}$ Hannan Quinn Information Criteria
} 


$$
\begin{aligned}
& \operatorname{MMSC}_{\text {BIC,n }}(\mathrm{k}, \mathrm{p}, \mathrm{q})=\mathrm{Jn}_{\mathrm{n}}\left(\mathrm{k}^{2} \mathrm{p}, \mathrm{k}^{2} \mathrm{q}\right)-(|q|-|p|) k^{2} \ln n \\
& \text { MMSC }_{\text {AIC,n }}(\mathrm{k}, \mathrm{p}, \mathrm{q})=\mathrm{J}_{\mathrm{n}}\left(\mathrm{k}^{2} \mathrm{p}, \mathrm{k}^{2} \mathrm{q}\right)-2 \mathrm{k}^{2}(|q|-|p|) \\
& \text { MMSC }_{\text {HQIC,n }}(\mathrm{k}, \mathrm{p}, \mathrm{q})=\mathrm{J}_{\mathrm{n}}\left(\mathrm{k}^{2} \mathrm{p}, \mathrm{k}^{2} \mathrm{q}\right)-\mathrm{Rk}^{2}(|q|-|p|) \ln \ln n \mathrm{R}>2
\end{aligned}
$$

$\mathrm{Jn}_{\mathrm{n}}(\mathrm{k}, \mathrm{p}, \mathrm{q})$ olmak üzere J, k değişkene sahip p. mertebeden ve bağımlı değişkenin q gecikmesinin moment koşullarına n örneklem düzeyine bağlı panel VAR'ın aşırı tanımlanan kısıtlarına ait istatistiğini göstermektedir (Abrigo \& Love, 2015). Buna alternatif kriter olarak da tam tanımlanmış GMM modeli ile determinasyon katsayısı (CD) tahmin edilebilmektedir. Determinasyon katsayısı panel VAR modeli tarafından açılanan değişim oranını sağlamaktadır. Bağımsız değişken $\psi$ 'nin kısıtsız kxk kovaryans matrisi olmak üzere:

$$
\mathrm{CD}=1-\frac{\operatorname{det}(\Sigma)}{\operatorname{det}(\psi)}
$$

Panel VAR modelinden yararlanılarak etki-tepki, varyans ayrıştırma ve Granger nedensellik analizi yapılabilmektedir. Etki tepki fonksiyonun güven aralıkları panel VAR parametreleri ve çapraz denklemlerin hata varyans-kovaryans matrisi veya Monte Carlo simülasyonu ile belirlenebilmektedir. Varyans ayrıştırmada her bir değişkenin öngürü hata varyansına katkısını izole etmek için $P$ matrisi tanımlanarak şoklar ortogonalleştirilmektedir. Ortogonalleştirilen şoklar $\mathrm{e}_{i t} \mathrm{P}_{-1}$, sahip olduğu $\mathrm{I}_{\mathrm{k}}$ kovaryans matrisi öngörü hata varyansının ayrıştırılmasına olanak tanımaktadır. h basamağındaki $m$ değișkeninin değișkenin öngörü hata varyansına katkısı i $\mathrm{i}_{\mathrm{k}}$ 'nın s. kolonunu göstermek üzere denklemdeki gibi hesaplanmaktadır (Abrigo \& Love, 2015).

$$
\sum_{i=0}^{h-1} \theta^{2}{ }_{m n}=\sum_{i=1}^{h-1}\left(i_{n}^{\prime} \mathrm{P} \Phi i_{m}\right)^{2}
$$

Uygulamada katkılar h basamağa göre n değișkeninin öngörü hata varyansı n'e göre normalleștirilmektedir.

$$
\sum_{i=0}^{h-1} \theta^{2}{ }_{n}=\sum_{i=1}^{h-1} i_{n}^{\prime} \Phi_{i}{ }^{\prime} \sum \Phi_{i} i_{n}
$$

Panel VAR analizinde nedensellik ilişkisi Granger nedensellik mantığına dayanmakla birlikte heterojenliğin önem kazandığı görülmektedir. Heterojenliğin dikkate alınmaması sapmalı sonuçlara neden olmaktadır. Panel nedensellik için kullanılacak model (Güriş, 2015, s. 297) denklem 8'de gösterilmiștir:

$$
\mathrm{y}_{\mathrm{it}}=\alpha_{\mathrm{i}}+\sum_{k=1}^{k} \gamma_{\mathrm{i}}(k) y_{i t-k}+\sum_{k=1}^{k} \beta_{\mathrm{i}}(k) x_{i t-k}+\varepsilon_{\mathrm{it}}
$$

Burada $\alpha_{\mathrm{i}}$ birime özgü etkileri, $\gamma^{(\mathrm{k})}$ ve $\beta$ (k) bütün birimler için aynı sayılmaktadır. Boş hipotez $\beta{ }^{(1)}=\ldots=\beta^{(\mathrm{k})}=0$ şeklinde oluşturularak bütün birimler için $\mathrm{x}$ değişkeninden y değişkenine nedensellik ilişsisinin olmadığı ifade edilmiştir (Güriş, 2015, s.297).

\section{Bulgular ve Tartışma}

Panel veri analizinin ilk aşamasında yatay kesit bağımlılığı test edilmiştir. Panel veride zaman boyutu yatay kesitten daha büyük olduğu için $(\mathrm{T}>\mathrm{N})$ Breusch Pagan LM testi tercih edilmiştir. Yatay kesit bağımlılığını tespit etmek için yapılan Breusch Pagan LM testinin boş hipotezi seride yatay kesit bağımlılığının olmadığıdır. Değișkenlere uygulanan testin neticesinde elde edilen olasılık değeri boş hipotezin kabul 
edilemeyeceğini göstermektedir. Bu sonuçlara göre panel veride yatay kesit bağımlılığı vardır.

\begin{tabular}{|l|l|l|l|l|}
\hline Değisçen & Olasılık Değeri & Karar & & \\
\hline kgüçl & 0.000 & $\mathrm{H}_{0}$ red & & \\
\hline libdem & 0.000 & $\mathrm{H}_{0}$ red & & \\
\hline kamuylsz & 0.000 & $\mathrm{H}_{0}$ red & & \\
\hline meclisks & 0.000 & $\mathrm{H}_{0}$ red & & \\
\hline $\mathrm{H}_{0}:$ Panelde yatay kesit bağımlılığı yoktur. & & & \\
\hline
\end{tabular}

Tablo3. Breusch Pagan LM Yatay Kesit Bağımlılığı Testi

Panel veri analizinin ikinci aşamasında ise Swamy S, Peseran ve Yagamata tarafından geliştirilen $\tilde{\Delta}$ homojenlik testi yapılmış ve panel veride eğimlerin homojen olup olmadığı sınanmıştır. Tablo 4'de sunulan test sonuçlarına göre tüm eğimlerin homojen olduğunu söyleyen boş hipotez kabul edilemez; dolayısıyla seriler heterojendir. Swamy S olasılık değeri model tahmini sonucu elde edilen eğim parametrelerinin heterojen olduğunu desteklemektedir.

\begin{tabular}{|l|l|l|l|}
\hline $\begin{array}{l}\text { Bağımlı Değişken } \\
\text { kamuylsz }\end{array}$ & $\begin{array}{l}\tilde{\Delta} \\
\text { olasılık }\end{array}$ & $\begin{array}{l}\tilde{\Delta}_{\text {adj }} \\
\text { olasılık }\end{array}$ & Karar \\
\hline kgüçl & 0.000 & 0.000 & $\mathrm{H}_{0}$ red \\
\hline libdem & 0.000 & 0.000 & $\mathrm{H}_{0}$ red \\
\hline meclisks & 0.000 & 0.000 & $\mathrm{H}_{0}$ red \\
\hline \multicolumn{2}{|l|}{} \\
\hline \multicolumn{2}{|l|}{ Swodel için homojenlik testi S } & 0.000 & Ho red \\
\hline
\end{tabular}

Tablo4. $\tilde{\Delta}$ ve Swamy Homojenlik Testi

Serilerde yatay kesit bağımlılığının ve heterojenliğin olması nedeniyle birim kök analizi için ikinci nesil MADF testi kullanılmıștır. Testin boş hipotezi serilerin birim kök içerdiğini söylemektedir. Yapılan birim kök testine göre kgüçl, libdem, meclisks değișkenlerinin test istatistiği değerleri kritik değerden yüksek olduğundan boș hipotez kabul edilemez, dolayısıyla test bu serilerin durağan olduğunu göstermektedir. kamuylsz değişkeninde ise test istatistiği kritik değerden küçük olduğu için boş hipotez red edilemez, yani serinin durağan olmadığına karar verilir. Bu durumda VAR modelinin işleyişi gereği birim kök içeren kamuylsz serisinin farkı alınarak analize dâhil edilmesi gerekmektedir.

\begin{tabular}{|l|l|l|l|l|}
\hline & \multicolumn{3}{|c|}{ MADF Birim Kök Testi Sonuçları } & \\
\hline Değişken & Test İstattistiği & Kritik Değer & Gecikme & Karar \\
\hline kgüçll & 64.11 & 49.62 & 3 & $\mathrm{H}_{0}$ red \\
\hline libdem & 51.78 & 49.62 & 3 & $\mathrm{H}_{0}$ red \\
\hline kamuylsz & 42.36 & 49.62 & 3 & $\mathrm{H}_{0}$ kabul \\
\hline
\end{tabular}




\begin{tabular}{|l|l|l|l|l|}
\hline meclisks & 87.7 & 49.62 & 3 & $\mathrm{H}_{0}$ red \\
\hline \multicolumn{4}{|c|}{$\mathrm{H}_{0}:$ Paneldeki birimlerin tamamının zaman serileri (I)'dir. } \\
\hline
\end{tabular}

Tablo 5. Panel Veri Birim Kök Testi Sonuçları

VAR modellerinde katsayı yorumlanmamaktadır. VAR modelinden hareketle Granger nedensellik, varyans ayrıștırma ve etki-tepki analizi yapılmıștır. VAR modelinin gecikme sayısının tespit etmek için başvurulan bilgi kriterleri bir gecikmenin uygun olduğunu göstermektedir.

\begin{tabular}{|l|l|l|l|}
\hline Gecikme & MBIC & MAIC & MQIC \\
\hline 1 & -197.88 & -61.74 & -117.05 \\
\hline 2 & -136.14 & -45.38 & -82.25 \\
\hline 3 & -69.034 & -23.65 & -42.1 \\
\hline
\end{tabular}

Tablo 6. Gecikme Sayısının Tespiti

\begin{tabular}{|l|l|l|l|}
\hline İçsel & Dişsal & Olasılık Değeri* & Karar \\
\hline kamuylsz & & & \\
\hline & kgüçl & 0.144 & $\mathrm{H}_{0}$ kabul \\
\hline & meclisks & 0.238 & $\mathrm{H}_{0}$ kabul \\
\hline & libdem & 0.009 & $\mathrm{H}_{0}$ red \\
\hline & tamamı & 0.031 & $\mathrm{H}_{0}$ red \\
\hline kgüçl & & & \\
\hline & kamuylsz & 0.901 & $\mathrm{H}_{0}$ kabul \\
\hline & meclisks & 0.099 & $\mathrm{H}_{0}$ red \\
\hline & libdem & 0.517 & $\mathrm{H}_{0}$ kabul \\
\hline & tamamı & 0.473 & $\mathrm{H}_{0}$ kabul \\
\hline meclisks & & & \\
\hline & kamuylsz & 0.794 & $\mathrm{H}_{0}$ kabul \\
\hline & kgüçl & 0.334 & $\mathrm{H}_{0}$ kabul \\
\hline & libdem & 0.521 & $\mathrm{H}_{0}$ kabul \\
\hline & tamamı & 0.72 & $\mathrm{H}_{0}$ kabul \\
\hline libdem & & & \\
\hline & kamuylsz & 0.08 & $\mathrm{H}_{0}$ red \\
\hline & kgüçl & 0.434 & $\mathrm{H}_{0}$ kabul \\
\hline & meclisks & 0.746 & $\mathrm{H}_{0}$ kabul \\
\hline & tamamı & 0.07 & $\mathrm{H}_{0}$ red \\
\hline Dişsal değişken içsel değişkenin nedeni değildir. \\
\hline Tabl Granger
\end{tabular}

Tablo 7. Granger Nedensellik Sonuçları

*Boş hipotez \%10’luk anlamlılık değeri dikkate alınarak değerlendirilmiștir. 
Granger nedensellik testinde dışsal değişkenin içsel değişkenin nedeni olup olmadığı sorgulanmaktadır. Buna göre Granger nedensellik testinde tabloda yer alan ilk satırda kgüçl, meclisks ve libdemin değişkenlerinin kamudaki yolsuzlukların nedeni olmadığı boş hipotezi sınanmaktadır. İlk satır için testten elde edilen bulgular, kadının güçlendirilmesi, meclisteki kadın sayısı değişkenleri ile kamudaki yolsuzluklar arasında bir nedensellik tespit edilemediğini fakat liberal demokrasiden kamudaki yolsuzluklara doğru bir Granger nedensellik olduğunu söylemektedir. İkinci satırda kadınların güçlendirilmesi ve parlamentodaki temsil düzeyleri arasında Granger olduğunu göstermektedir. Yapılan Granger nedensellik analizi kamudaki yolsuzlukla liberal kurumlara doğru nedenselliği de doğrulamaktadır. Dolayısıyla yapılan analizden kamudaki yolsuzluklarla liberal demokratik kurumlar arasında iki yönlü nedensellik tespit edilmektedir.

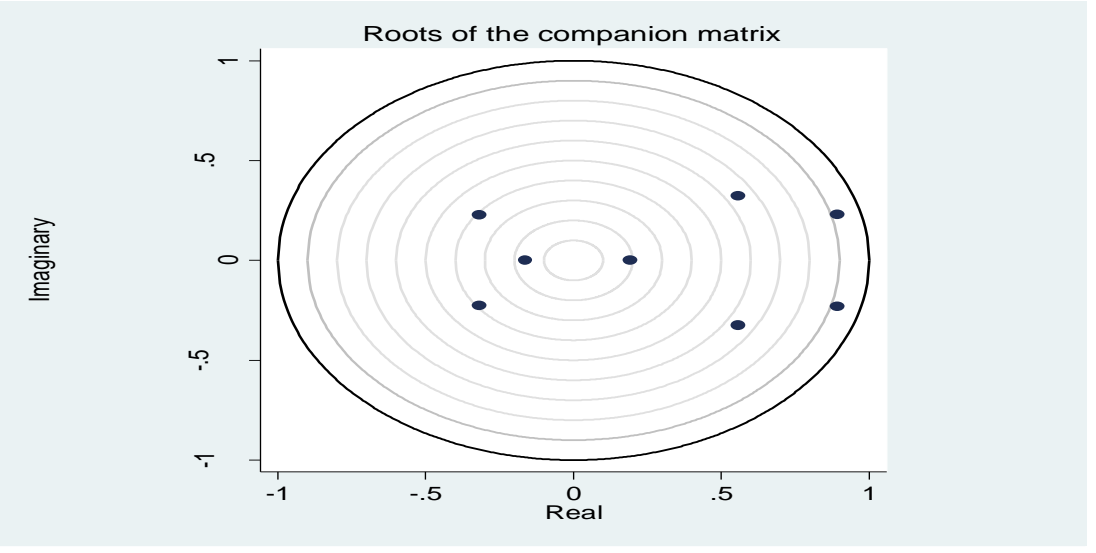

Grafik1. İstikrar Koşulunun Sağlanması

Panel VAR modelinin istikrar koşullarını sağlayıp sağlamadığı sınamak için özdeğerlerin < |1| olup olmadığına bakılmaktadır. Grafikte görüldüğü gibi özdeğerler 1 'den küçük ve birim çemberin içindedir.

\begin{tabular}{|c|c|c|c|c|}
\hline \multicolumn{4}{|c|}{ Varyans Ayrıștırması Sonuçları* } & \\
\hline Tepki Değişkeni ve Öngörü zamanı & & & & \\
\hline kamuylsz & kamuylsz & kadıngüçl & meclisks & libdem \\
\hline 0 & 0 & 0 & 0 & 0 \\
\hline 1 & 1 & 0 & 0 & 0 \\
\hline 2 & 0.81 & 0.025 & 0.002 & 0.16 \\
\hline 3 & 0.79 & 0.03 & 0.002 & 0.18 \\
\hline 4 & 0.74 & 0.07 & 0.003 & 0.18 \\
\hline 5 & 0.62 & 0.09 & 0.013 & 0.28 \\
\hline 6 & 0.48 & 0.09 & 0.026 & 0.41 \\
\hline 7 & 0.39 & 0.077 & 0.038 & 0.5 \\
\hline 8 & 0.33 & 0.67 & 0.047 & 0.55 \\
\hline
\end{tabular}




\begin{tabular}{|l|l|l|l|l|}
\hline 9 & 0.3 & 0.061 & 0.054 & 0.58 \\
\hline 10 & 0.29 & 0.061 & 0.057 & 0.59 \\
\hline
\end{tabular}

Tablo 8. Varyans Ayrıştırması Sonuçları*

* Rakamlar yuvarlanarak tablolaştırılmıştır.

VAR modelinden hareketle serilere varyans ayrıștıması uygulandığında kamudaki yolsuzlukların öngörü varyansı bileșenlere ayrılarak incelenmiştir. Buna göre kamudaki yolsuzlukların varyansında ortaya çıkan değişmenin birinci gecikmede tamamı, ikinci gecikmede yaklaşı \%80'i yolsuzlukların kendisi ile açıklanırken, gecikme sayısı arttıkça kamuda ortaya çıkan yolsuzluklarda liberal demokratik kurumların açıklayıcı etkisinin arttığı görülmektedir. Varyans ayrıștırması, kamuda ortaya çıkan yolsuzlukların oldukça düşük bir oranını kadının güçlendirilmesi ile açıklamakla birlikte parlamentodaki kadın sayısının gecikme sayısı arttıkça daha büyük etkiye sahip olduğu görülmektedir.

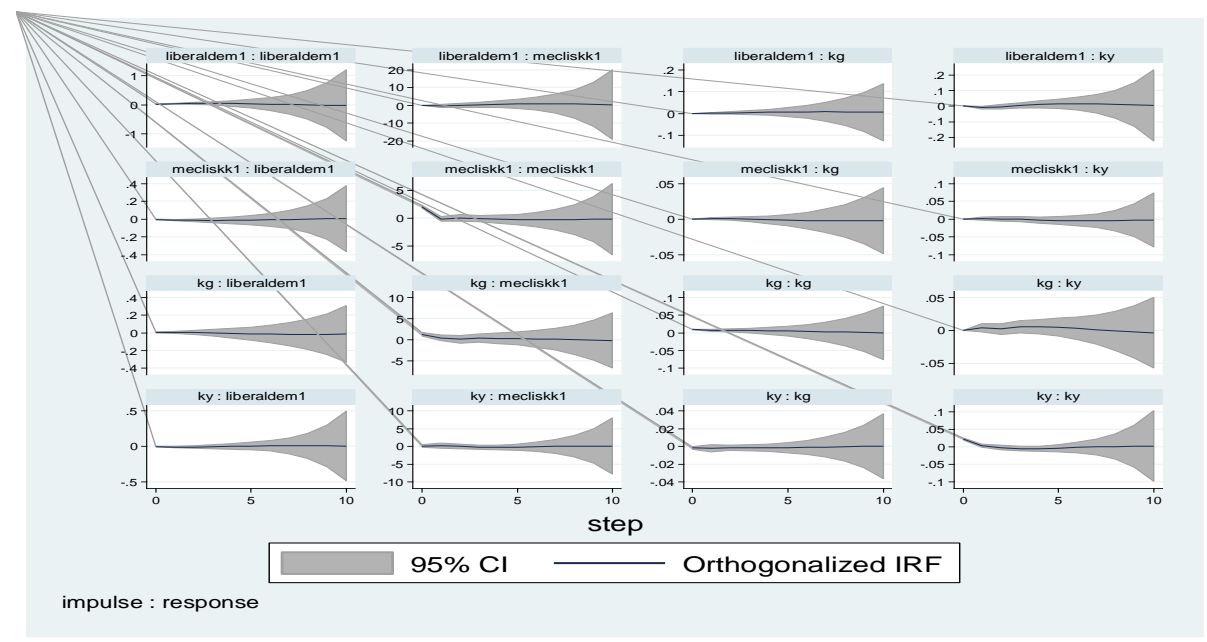

Grafik 2. Etki-Tepki Analizi Sonuçları

Etki tepki grafiklerinde $\mathrm{x}$ ekseni kaç dönemin analize dâhil edildiğini göstermektedir. Buna göre grafiklerde 10 dönem için etki tepki analizi incelendiği görülmektedir. Birinci satırda liberal demokrasiyle diğer değișkenler arasındaki etki tepki fonksiyonları gösterilmiştir. Buna göre soldan sağa doğru grafikleri yorumladığımızda liberal demokratik kurumlarda bir standart sapmalık şok meydana geldiğinde kamudaki yolsuzlukların pozitif yönlü tepki verdiği tepkinin beşinci dönemden sonra arttığı görülmektedir. Dördüncü satırda kamu yolsuzluklarına bir standart sapmalık şok verildiğinde liberal demokratik kurumların artan negatif tepki verdiği görülmektedir.

Elde edilen bulgular, liberal kurumlar ile kamudaki yolsuzluklar arasındaki ilişkiyi desteklemiş; kadınların güçlendirilmesi ve yolsuzluklar arasında doğrudan ve anlamlı bir ilişki kurulamadığını göstermiștir. Bu bulguların Dollar, Fisman ve Gatti (1999)'nin ve Jha ve Sarangi (2018)'in cinsiyet ve yolsuzluklar arasında doğrudan ilişki kuran çalışmalarından farklılaşmakla birlikte yolsuzlukla mücadelede kadınların siyasal katılımının yolsuzlukla mücadelede etkili olabileceği tezi ile örtüşmektedir. Öte yandan elde edilen bulguların yolsuzlukla mücadelede liberal kurumların önemine vurgu yapan 
Sung (2012) ile örtüştüğü görülmektedir. Dollar, Fisman ve Gatti (1999) ve Jha ve Sarangi (2018) kadınların siyasete katılarak karar alma mekanizmalarında yer almalarının yolsuzlukla mücadele de önemli bir adım olduğu sonucuna ulaşmış fakat hukukun üstünlügü ilkesini benimseyen liberal kurumların yolsuzlukla mücadele mekanizmalarındaki rolünü vurgulamamışlardır. Sung (2012)'nin bu eksik noktaya itiraz ettiği ve elde ettiği bulgularla liberal kurumların yolsuzlukla mücadeledeki önemini daha açık ortaya koyduğu görülmektedir. Fakat Sung(2012)'ın ampirik ölçüm hatalarını da gidererek bu bulguya ulaşmasına rağmen yazılı kurallardan oluşan formel ve yazısız kuralları kapsayan enformel kurumların birey ve toplum üzerindeki etkisinin anlaşılması ve somut olarak ortaya konmasının zorluğu da açıktır. Nitekim liberal kurumların işlerlik kazanması formel kurumların toplumda karşılıklı güven, işbirliği yazılı olmayan kuralları kapsayan enformel kurumlar ve kültürel öğelerle sınırlanmaması da önemli bir etkendir. Bu sınırlama MDA ülkelerine ait verilerden izlenmektedir.

Çalışmaya konu olan MDA ülkeleri 2004 yılından itibaren Avrupa Birliği üyesi olmuş; formel olarak siyasal liberal değerleri benimsemişlerdir. Fakat geçmiş kurumların etkisinin halen toplumda var olması ve enformel ilișkileri beslemesi nedeni ile kamudaki yolsuzlar bertaraf edilememiștir. Benzer bir çelișki cinsiyet eșitliği konusunda da söz konusudur. Liberalizmin gerektirdiği ekonomik, sosyal ve siyasal eşitliğin halen sağlanamadığı cinsiyet eșitsizliği ile ilgili göstergelerden izlenmektedir. Bu bakımdan liberal kurumların kamudaki yolsuzluklar ve cinsiyet eşitliği konusundaki etkisinin enformel kurumsal yapıdan ampirik olarak ayrıștırılmasının oldukça güç olduğu görülmektedir.

\section{Sonuç}

Kamu makamlarının özel çıkarlar için kullanılması anlamına gelen yolsuzluk yarattığı ekonomik, sosyal ve siyasal etkileri itibariyle mücadele edilmesi gereken bir suiistimal alanıdır. Bu nedenle kamuda yaşanan suiistimallerin önüne geçmek için ulusal ve uluslararası kuruluşların da teşvikiyle birçok araştırma yapılmaktadır $\mathrm{Bu}$ araştırmalardan bir kısmı yolsuzlukla mücadele için kadın yöneticilerin sayısının artmasının iyi bir çözüm olabileceği savunmaktadır. Fakat bu görüşe karşı geliștirilen ve demokratik kurumların tesis edilmesinin yolsuzlukla mücadelede daha etkin bir çözüm olacağını görüşünü savunan araştırmacılar, cinsiyetin yolsuzlukları engellemekte istenen sonuçları yaratamayacağını ampirik olarak ortaya koymaktadır. Bu yaklaşım, denge denetim mekanizmalarının tesis edilmesi, hukukun üstünlüğü gibi liberal demokratik değerlerin yolsuzlukla mücadele de toplumsal cinsiyet ve kadın rolünden daha etkin olduğunu savunmaktadırlar. Konun cinsiyet ile kurulan bağı, demokrasinin niteliğinin kadınların güçlendirilmesi ve kadınların demokratik karar alma mekanizmalarında yer bulmaları bakımından öneminde yatmaktadır. Dolayısıyla demokratik değerlerin geliştirilmesi, yolsuzlukla mücadele kadar dünyadaki yoksulların büyük kısmını oluşturan kadınların yaşam koşullarının iyileștirilmesi bakımında da önem kazanmaktadır.

Konu MDA ülkeleri açısından ampirik olarak değerlendirildiğinde de liberal demokratik kurumlarla yolsuzluk arasında istatistiksel olarak anlamlı ilişki kurulurken, cinsiyet değişkenleri ile ilgili böyle bir sonuca varılamamıştır. MDA ülkelerinde cinsiyet eşitsizliği kadınların özellikle ekonomik ve siyasal yaşamda etkin rol alamamalarıyla kendini göstermektedir. Bu durum liberal demokratik kurumların hem kadınların güçlendirilmesi hem de yolsuzlukla mücadele alanında daha geniş bir çerçeve sunduğunu da desteklemektedir. Liberal demokratik kurumların varlığı yolsuzlukla mücadele kadar ekonomik ve siyasal haklardan yoksun bırakılan kadınların yașam koşullarının iyileștirilmesi içinde bir çözüm yolu olarak görülmektedir. 
Bu konuda yapılacak gelecek çalışmaların yolsuzlukla mücadelede geçmiş kurumların etkisinin nasıl bertaraf edileceğini ele almanın yanı sıra kadınların uğradığı ayrımcılık ve dışlanmanın kaynağı olan sosyal kurumların kapsayıcılığını sağlamak için atılacak adımları incelemesinde yarar vardır.

\section{KAYNAKÇA}

ABRIGO, Michael, R.M. \& LOVE, I. (2015). Estimation of panel vector autoregression in Stata: A package of programs. Erişim tarihi:12.10.2019, http://paneldataconference2015.ceu.hu/Program/Michael-Abrigo.pdf .

AKHMETOVA, E. (2014). Women and corruption. Islam and Civilisiation Renewal, Vol. 5 (2) , 273-276.

ALATAS,V., CAMERON, L., CHAUDHURI A., ERKAL, N.\& GANGADHARAN, L. (2008). Gender, culture, and corruption: Insights from an experimental analysis. Southern Economic Journal, Vol. 75 (3), 663-680.

BARNES, T., D.\& BEAULIEU, E. (2014). Gender stereotypes and corruption: How candidates affect perceptions of election fraud. Politics and Gender, Vol. 10, 365-391. doi:10.1017/S1743923X14000221

BATORY, A. (2012, January). Why do anti-corruption laws fail in Central Eastern Europe? A target compliance perspective. Regulation \& Governance, 1-18. doi:10.1111/j.1748-5991.2011.01125.x.

BRANISA, B., KLASEN, S.\& ZIEGLER, M. (2010). Why we should all care about social institutions related to gender inequality? the German Development Economics Conference, Hannover 2010, No. 50.

BREUSCH, T., S. \& PAGAN, A.,R. (1980). The langrange multiplier test and its applications to model specification in econometrics. The Review of Economic Studies, Vol. 47(1), Econometrics Issue, 239-253.

BULĞURCU, B.\& ÖZDEMİR, P. (2015). Geçiş ekonomilerinde sağlık harcamalarının etkinliği üzerine bir inceleme. Ege Akademik Bakış, Vol. 15 (4), 523-537.

CANOVA, F., CICCARELLI, M.(2013). Panel vectors autoregressive models survey. European Central Bank Eurosystem Working Paper Series, No:1507.

DOLLAR, D., FISMAN R. \& GATTI, R. (1999). Are women really the "fairer" sex? Corruption and women in government. Policy Research Report on Gender and Development Working Paper Series, No. 4.

DININIO, P, KPUNDEB, J. S. \& LEIKEN, R. (1999). A Handbook of Fighting Corruption Center for Democracy and Governance Bureau for Global Programs, Field Support, and Research U.S. Agency for International Development Washington, D.C.

ESAREY, J.\& SCHWINDT-BAYER, L., A.(2017). Women's representation, accountability and corruption in democracies. British Journal of Political Science, 48, 659-690.

FRANK, B., LAMBSDORFF, J., G.\& BOEHM, F.(2011). Gender and corruption: lessons from laboratory corruption experiments. European Journal of Development Research Vol. 23, 59-71. doi:10.1057/ejdr.2010.47.

GOETZ, A., M. (2007). Political cleaners: Women as the new anti-corruption force? Development and Change, Vol.38(1), 87-105.

GÜRIŞ, B.(2015). Panel Vektör Otoregresif Modeller ve Panel Nedensellik içinde Stata ile Panel Veri Modelleri (Ed. S. Güriş). İstanbul: DER Yayınları, 291-304. 
JHA, KUMAR, J.\& SARANGİ, S. (2018). Women and corruption: What positions must they hold to make a difference? Journal of Economic Behavior \& Organization, Vol. 151, 219-233.

MARTIN, Y., P. (2004).Gender as a social institutions. Social Forces, Vol. 82(4), 1249-1273.

NARAYAN, PARESH K., NARAYAN SEEMA (2007). Mean reversion in stock prices:

New evidence from panel unit root tests. Studies in Economics and Finance, 24(3): 233-244.

ÖZDEMIR ÇUKADAR, P.(2017). Piyasalaşma sürecinin geçiş ekonomilerinde refah devleti anlayıșı üzerine etkileri. Maliye Dergisi, Sayı 173, 244-264.

RIVAS, F., M. (2008). An experiment on corruption and gender. ThePapers 08/10, Department of Economic Theory and Economic History of the University of Granada..

QUALITY OF QOVERMENT INSTITUTE (2019). Standart Data: Time Series. Universtiy of Gothenburg, Sweden. Erişim tarihi:02.11.2019, https://qog.pol.gu.se.

SELEIM, A.\& BONTIS, N.(2009). The relationship between culture and corruption: A Cross-national study. Journal of Intellectual Capital, Vol. 10(1), 165-184.

STENSÖTA, H., WÄNGNERUD, L. \& SVENSSON, R. (2015). Gender and corruption: The mediating power of institutional logics. governance: An International Journal of Policy, Administration, and Institutions, Vol. 28(4), 475-496.

SUNG, H.(2012, October). Women in government, public corruption, and liberal democracy: A panel analysis. Crime Law and Social Change, 58, 195-219.

SUNG You, J \& KHAGRAM, S.(2004). A comparative study of inequality and corruption. the John F. Kennedy School of Government Harvard University, Working Paper No:22.

TAYLOR, P.,M. \& SARNO, L.(1998). The behavior of real exchange rates during the post-Bretton Woods period. Journal of International Economics, Vol. 46, 281-312.

TORGLER, B.\& VALEV, N., T. (2010, October). Gender and public attitudes toward corruption and tax evasion. Contemporary Economic Policy, 1-28.

WORLD ECONOMIC FORUM (2018). The Global Gender Gap Report. Cologny/Geneva. Switzerland.

YERDELEN TATOĞLU, F.(2020). İleri panel veri analizi. İstanbul: Beta Yayınları

\section{Summary}

Corruption is abuse of public office for private gains by indivudial or groups. It is discussed in literature that women and men have behavioural patterns related to their gender and these patterns' can affect corruption tendency. Certain part of empirical researches findings support that women are more responsive to social and economic events, more helpful and stick to ethical value. Related to these approaches, more women should be in decision making mechanism to struggle with corruption. This approach is also shared and supported by international institutions such as World Bank. Other group of researches support that there is no significant relationship between struggling with corruption and gender. Related to this approach, the most important thing is to establish liberal democratic institutions for fighting corruption.

Aim of this study is to seek gender and corruption relation in Central and Eastern European Countries where had high level of corruption during socialist regime accompanied with sustaining impression of past institutions. Being a member of European Union do not change past institutions heritage too. These countries had been subjected to economic, political and social shocks following the regime changes and they established liberal 
institutions. However these countries show significant differences in gender equality and gender gap.

It is applied panel VAR (vector autoregressive) analysis to examine women's empowerment, the representation of women in parliament and liberal democratic institutions linkages with corruption As a result of the analysis, Granger causality is not found between gender and corruption in Central and Eastern European countries. The findings indicate that there is a causality between women's empowermnent and levels of representation in parliament, moreover anaysis confirms the causality between corruption and liberal institutions. When variance decomposition is applied to the panel data, it is seen that the deviation in variance of corruption is explained totally by corruption in first lag, $\% 80$ explained in second lag, additonaly while number of lag increases, liberal democratic institutions effect on corruption increase too. Variance decomposition explains low proportion of corruption with women empowerment, altough number of women in parlianment have positive impact on corruption related to lag length. According to impulseresponse analysis result, when one percent standart deviation shock occur in corruption variable liberal democratic institutions react negatively and response increases after the fifth period. 